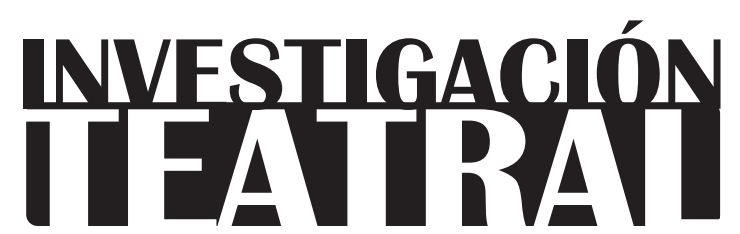

Revista de artes escénicas y performatividad

Vol. 9, Núm. 13

abril-septiembre 2018

Segunda época

ISSN impreso: 1665-8728

ISSN electrónico: 2594-0953

Universidad Veracruzana

\title{
Los talleres Drag King: Una metodología feminista de investigación encarnada
}

\author{
Alba Pons Rabasa*
}

\footnotetext{
* Universidad Autónoma Metropolitana Unidad Iztapalapa, México.

e-mail:alba_pons@cieg.unam.mx
}

Recibido: 30 de agosto de 2017

Aceptado: 09 de febrero de 2018 


\title{
Los talleres Drag King: Una metodología feminista de investigación encarnada
}

\section{Resumen}

En el marco de las críticas post-estructuralistas a la identidad, propongo el drag king como una metodología feminista de investigación encarnada que nos permite reflexionar corporalmente en torno a la identidad de género en tanto experiencia, pero también en tanto categoría teórica y política. A partir de dicho ejercicio performático y performativo se evidencian los desbordamientos y las tensiones existentes entre la propia experiencia y la representación de la misma. En un primer momento, ubicaré el origen de los talleres Drag King como herramienta de concienciación feminista, para después exponer lo que tal experiencia supone en una trayectoria vital específica a través de un breve relato autoetnográfico y, a partir de allí, problematizar la identidad de género.

Palabras clave: autoetnografía, investigación encarnada, identidad de género, performatividad, performance.

\section{Drag King Workshops: A Feminist Embodied Research Methodology}

\begin{abstract}
Based on post-structuralist critiques of identity, this paper argues that drag king performances may serve as a feminist embodied research methodology that allows us to think of gender identity as corporeal experience, but also as a theoretical and political category. These performative exercises make clear the overflows, tensions and gaps between first hand experiences and the way in which these might be represented and read by others. The origin of the Drag King workshops as a feminist awareness technique is briefly discussed. This is followed by a self-reflexive ethnography in which the author explains how drag king performances affected her own life history and how this led her to a problematization of gender identity.
\end{abstract}

Keywords: auto-ethnography, embodied research, gender identity, performativity, performance. 


\section{Los talleres Drag King: Una metodología feminista de investigación encarnada}

\section{Introducción}

E n este artículo problematizo el concepto de identidad de género a partir de la actuación drag king, considerándola como una metodología feminista de investigación encarnada. ${ }^{1}$ A través de un relato autoetnográfico, muestro la potencialidad de esta herramienta, tanto para reflexionar corporalmente en torno a nuestra identidad de género como para la producción de conocimiento teórico en nuestras investigaciones.

En el marco de las críticas post-estructuralistas a las políticas de la identidad, este ejercicio performático y performativo problematiza precisamente el concepto de identidad, evidenciando los desbordamientos y tensiones existentes entre la experiencia y la representación de la misma, a través de las categorías identitarias. Al mismo tiempo, permite realizar dicha problematización desde la propia corporalidad y subjetividad, teniendo por lo tanto un efecto transformador sobre nuestra práctica investigativa misma, (pues "el performance [...] es una práctica y una epistemología, una forma de comprender el mundo y un lente metodológico") (Taylor, Performance 31).

No es mi intención hacer aquí una genealogía del drag king en tanto que fenómeno contemporáneo, sino más bien ubicar el origen de los talleres como herramienta de concienciación feminista para, en un segundo momento, exponer lo que tal experiencia ha supuesto en una trayectoria vital específica a través de algunos trazos autoetnográficos. A

${ }^{1}$ El término drag se utiliza en lengua inglesa para referirse a un tipo de actuación travesti. Drag queen es el hombre travestido de mujer, mientras que drag king es la mujer travestida de hombre [n. del ed]. 
partir de ello propondré una problematización de la identidad de género como concepto analítico y político, para finalmente convocar a la utilización de esta técnica en la investigación encarnada.

Esbozar una autoetnografía posibilita reflexiones corporales y experienciales que complejizan los planteamientos analíticos en torno al tema que queremos trabajar. Lo que en este caso, concretamente, constituye un claro intento por desestabilizar ya no solamente el género y la heteronormatividad, sino también algunos principios objetivistas que suelen subyacer a este tipo de trabajos, deviniendo obstáculos para la creación de conocimiento situado y encarnado. Siguiendo a Caroline Ellis, "esta aproximación [la autoetnografía] desafía las formas canónicas de hacer investigación y de representar a los otros (Spry 2001), a la vez que considera a la investigación como un acto político, socialmente justo y consciente (Adams y Holman Jones 2008)" (“Autoetnografía: un panorama” 50).

Si de acuerdo con la autora citada (2000), podemos ubicar dentro de la autoetnografía diferentes subtipos, el presente artículo pretende mostrar un uso de esta técnica como parte de la etnografía reflexiva característica de la investigación feminista (Ellis, "Autoetnography" 740). Se trata, en efecto, de producir ciertos trazos autoetnográficos ${ }^{2}$ desde los cuales profundizar en el análisis de algunos aspectos relativos a la cultura de género, en pos de generar un distinto encuentro o diálogo entre nuestros trabajos de investigación feminista que nos permita complejizar y encarnar el pensamiento que producimos.

\section{Orígenes de los talleres Drag King}

Los talleres Drag King ${ }^{3}$ nacieron de manos de la artista y activista Diane Torr en la ciudad de Nueva York hacia 1990. Casi por casualidad, esta feminista escocesa, performancera y educadora, experimentó en carne propia lo que implica una transformación

${ }^{2}$ Hablo de trazos y apuntes autoetnográficos porque no presento en este artículo una autoetnografía completa; más bien realizo un ejercicio narrativo que recupera parte de una experiencia vivida para pensar y analizar algunos aspectos útiles a mi trabajo de investigación y a mi experiencia personal. Se trata de un esfuerzo por relatar la experiencia drag king como epifanía en mi trayectoria vital, considerándola al mismo tiempo como una técnica que me ha permitido encarnar - es decir, pensar y hacer inteligible desde la experiencia corporal-, ciertos análisis sobre el género, el cuerpo y la sexualidad. Estos análisis, a su vez, resultan imprescindibles para mi trabajo de investigación, en tanto que cuestionan el lugar desde el cual producir conocimiento sobre los temas mencionados, así como las formas de hacerlo y las representaciones que se generan en la producción misma de conocimiento.

${ }^{3}$ Se escribe Drag King con mayúsculas cuando se hace referencia a los talleres de Diane Torr [n. del ed.]. 
como la del drag en el espacio público. Los efectos emocionales, corporales y subjetivos de dicha experiencia, le animaron a investigar e impartir los talleres en torno a este tipo de performance.

A través de la enseñanza de diversas técnicas y usando cierta metodología teatral para representar masculinidades, Torr pretendía que sus talleristas pasaran ${ }^{4}$ como hombres y pudieran "experimentar la autoridad del hombre, su territorio y sus derechos" (Halberstam, Masculinidad Femenina 280).

La descripción es de un libro de 2008 que dedica un capítulo completo al fenómeno, cuyo autor/a queer, Jack/Judith Halberstam, propone una taxonomía de los diferentes tipos de drag king que pueden hallarse en el espectáculo. Según él/ella, los talleres de Torr quedarían circunscritos a la categoría "mimetismo de hombres", pues a diferencia de otros tipos de performances, en ellos se sigue vinculando y asociando la masculinidad a los varones, reificando así tal articulación y reproduciéndola sin proponer otras "reconstrucciones de la masculinidad".

Diane Torr y su metodología constituyen un referente ineludible en el campo de los talleres Drag King. En el libro que publicó junto al crítico de arte Stephen Bottoms, Torr hace un recorrido por su historia en el mundo de la performance feminista - al que llegó con una acción que realizó al lado de sus compañeras de trabajo del club de gogo's-, y a través de sus diferentes formaciones artísticas (Release dance, Contact Improvisation y otras danzas); camino que recorrió con especial interés en indagar a profundidad acerca del cuerpo y las construcciones sociales de género. En un contexto de intensos debates dentro del feminismo sobre las expresiones de la sexualidad de las mujeres, la pornografía, el trabajo sexual y la violencia, sus performances adquirieron una fuerte carga provocadora y cuestionadora del esencialismo y de los roles estereotipados de género. ${ }^{6}$

${ }^{4}$ Se utiliza aquí el verbo "pasar" y el sustantivo "pasabilidad" para indicar la capacidad de ser reconocida/o con el género que deseas ser interpretada/o, (cuando no se corresponde este último con tu género registral $o$ asignado al nacer).

5 Tanto Torr como Halberstam disponen de una genealogía propia del término y la práctica del drag king. Paul B. Preciado reconoce en Torr a la creadora misma del término (2004), pero Torr lo atribuye a Johnny Sciencie (Torr y Bottoms 2010, 99). Más allá de la cuestión de la autoría, lo cierto es que Torr en 1990 dio su primer taller Drag King, mientras que Del La Grace Volcano afirma, en The Drag King Book (1999) copublicado con Halberstam, que en 1985 asistió por primera vez a un "acto drag king". Esta última publicación se puede considerar como pionera en el estudio del tema, a partir de fotografías de los primeros rastros de una cultura drag king emergente ubicada en San Francisco, Nueva York y Londres (Volcano y Halberstam 1999, 10). Tales trabajos constituyen sin duda un archivo histórico fundamental.

${ }^{6}$ En aquellos momentos, el conflicto entre abolicionistas y pro-sex en Estados Unidos era muy intenso y las performances de gogo de Torr pretendían cuestionar la relación que las primeras veían entre sexualidad, erotismo y dominación masculina. Ver Torr y Bottoms (2010). 
En abril de 1989, cuando Diane Torr ya era conocida por algunos de los personajes masculinos de sus performances, fue convocada por Annie Sprinkle (feminista pro-sex estadounidense) para modelar las fotografías del "antes" y el "después" que ilustrarían una entrevista realizada a Johnny Sciencie, fundador de uno de los primeros grupos neoyorquinos de transexuales y cross dressers female-to-male, "F2M Fraternity". El mismo día en que se inauguraba la Whitney Museum's Biennial Exhibition, se llevó a cabo la sesión de fotos, al finalizar la cual la escultora Sonja Oudendijk - la amiga alemana que acompañaba a Torr-, se precipitó a partir hacia el evento y presionó a su acompañante para salir tal como estaba caracterizada. Nadie reconoció a Torr al llegar, lo que le permitió observar el evento desde el rol del voyeur y experimentar cómo la identidad es relativa y relacional (Torr, Sex, Drag 198). Notó que al pasar como hombre, cambiaba automáticamente el lugar que se le asignaba socialmente y que las interacciones eran totalmente distintas. Todo ello la motivó a proponerle a Johnny Sciencie la planeación de un taller, en el que éste pudiera transmitir las técnicas de transformación corporal que conocía, mientras la propia Torr proponía herramientas para la creación física de personajes masculinos (94-100). Así fue cómo comenzó a explorar e investigar mediante talleres desde 1990, ${ }^{7}$ abriéndosele "la posibilidad de crear, a través del aprendizaje teatral de la masculinidad, un nuevo territorio para la experiencia del cuerpo".

\section{Apuntes para una autoetnografía drag I. Fragmentos corpobiográficos.}

El drag king me ha acompañado de uno a otro lado del océano, en experiencias que han ocurrido en contextos tan diversos como cafés-teatros de Quito (algunos muy precarios y otros glamourosos), los centros sociales okupados de una Barcelona en transformación o el activismo transfeminista autónomo radical. También he impartido talleres en centros de salud de la administración pública del Estado español, así como en escuelas, jornadas académicas de la Universidad de México y hasta en un centro cultural bonaerense. Mi presente no tiene nada que ver con mi ayer y el drag king tiene un papel fundamental en este recorrido transformador.

7 Tal como relata en su libro, antes de ofrecer estos talleres con Johnny Science, los personajes masculinos de Torr evidenciaban su carácter de artificio, pues ella todavía no conocía las técnicas que permitían que el personaje "pasara" como hombre. Eso fue lo que le aportó la experiencia transgenérica de Johnny Science (Torr y Bootoms, Sex, Drag 98).

${ }^{8}$ Como relata Beatriz Preciado (2004) a partir de lo que Diane Torr expone en la película de Gabriel Baur, Venus Boyz (2002). 
Es necesario advertir que una mirada retrospectiva implica recrear el pasado atendiendo al carácter performativo de la memoria. El drag, como una suerte de epifanía en mi historia de vida, será aquí revisitado para proponer ciertas reflexiones analíticas encarnadas a través de un análisis autoetnográfico, que nos permitan por un lado cuestionar el concepto de identidad, y por el otro, las formas en que hacemos investigación. Digo "autoetnográfico" porque - siguiendo a Ellis (2015) - además de tratarse de un relato con carácter autobiográfico, pretende utilizar la experiencia personal para ilustrar ciertas facetas de la experiencia cultural, poniendo en juego para ello algunas herramientas metodológicas y literatura científica.

Fui una "niña-niña". No recuerdo haber tenido conflictos con ello ni mi madre me ha relatado alguno. De hecho, creo que era la "niña-niña" más feliz del mundo, jugando con muñecas, a mamás y a papás, a hacer de cantante, bailarina y demás ejercicios de feminidad. Desde los cuatro hasta los dieciocho años recibí clases de ballet clásico: feminidad y disciplina. Aunque nunca me había quejado, el día en que a los quince años me pusieron una báscula enfrente no quería pesarme (había llegado el momento de añadir la disciplina alimentaria a la disciplina corporal del ballet). Comencé a odiar a mi profesora, asumí que no me gustaba mi cuerpo y me resistí a regular mi alimentación.

Hice también patinaje y teatro. En el baloncesto de la escuela duré poco. En las clases de gimnasia, mis compañeros se reían de mi forma de correr. La adolescencia fue una etapa que me pareció terrible y llegó antes de lo esperado: la menstruación y esas dos nuevas desconocidas que entonces me abrían paso en la vida, mis tetas. Me resistía llorando cada noche sin motivo alguno. Era solamente tristeza. "Llora hija, sácalo..." Y ya.

Poco a poco esas lágrimas nocturnas dejaron de caer y mis manos comenzaron a descubrir mi cuerpo. Al poco tiempo, también otras manos y cuerpos ajenos se mezclaban con mi piel en mis primeros rituales de "amor" (sexo de principiantes, poco placer y mucha curiosidad). Sexo heterosexual sin cuestionamientos. Ya era una mujer heterosexual.

Tuve que conocer lo trans* y el feminismo para interrogarme sobre mi ser mujer y mi ser heterosexual, sobre mi identidad y mi deseo. A partir de ahí, nunca más me he alejado de estos lugares; lo trans* y el feminismo son actualmente la base de mis reflexiones y transformaciones: de mis pensamientos acerca de la heterosexualidad obligatoria, el binarismo de género, el encuentro erótico entre mujeres, el sistema sexo-género, la performatividad, la performance y muchos otros conceptos y prácticas que me han ayudado a leer la realidad, entenderla e ir mutando.

No fue sino hasta 2007 - cuando tomé un taller Drag King- que me pasaron realmente por el cuerpo ciertos cuestionamientos que llevaba años haciéndome de manera abstracta. Entonces entendí por fin ciertas teorías que había leído y me sabía de memoria, sin haberlas comprendido a profundidad hasta aquel momento. Yo vivía por entonces en 
Quito con mi compañera de cama y de activismo, y para una fanática del teatro social, feminista y obsesiva de lo trans", el título "Teatralidades del género" — como se llamaba el taller - resultaba suculento. Mi compañera, por su parte, ya hacía drag king en un humilde y glamouroso café-teatro, El Dionisios, donde yo recientemente había experimentado con el drag queen.

En "Teatralidades del género" conocí a la artista Susana Cook. ${ }^{9}$ Ella fue directa con su pregunta: “¿Han traído su ropa?” La noche anterior había estado probándome medio closet de mi compañera con su supuesta ropa "de hombre" y no encontré nada. En la tienda de la Casa del Árbol hallé finalmente un traje de señor, que fue lo que me puse aquel primer día del taller. Un traje de señor para performar una masculinidad blanca, burguesa y heterosexual.

Susana nos enseñó las técnicas para travestirnos, los trucos para perfomar una masculinidad paródica que "pasara" como tal. Aprendí a hacer la barba, el "paquete", a vendarme los pechos, y después el caminar, respirar, fumar, bailar... hablar. En ningún momento, sin embargo, conseguí entrar del todo en ese alter ego; ${ }^{10}$ me sobraban partes de mi cuerpo y me faltaban accesorios y actitud. "Se me chorreaba la feminidad por todos lados" y eso me enfureció, me entristeció y me obligó a preguntarme muchas cosas que antes no me había preguntado.

Veía a mis compañeras reírse, divertirse, fluir. Habían conseguido performar masculinidad, reírse de ella, parodiarla y, por tanto, pensar en cómo se habían construido como "mujeres copia". Yo no.

Esa noche tenía muy claro que al día siguiente no iba a volver al taller. Mi compañera me dijo: "Alba, no lo fuerces, busca una masculinidad más afín contigo, con tu cuerpo; aunque no te guste, aprovecha aquello de tu cuerpo que también pueda ser parte de esa masculinidad, no fuerces a un ejecutivo. No solo estamos representando masculinidad, sino que son personajes cruzados por otras características, busca el tuyo".

Era cierto: no hay hombres a secas, no existen. Existen hombres blancos, heterosexuales, de clase alta, ejecutivos de multinacionales. Existen raperos de barrio, gitanos y chavos que limpian los cristales de los coches. Maricas. "Fresas" diseñadores de ropa que viven en los barrios bohemios de capitales. Solo tenía que encontrar al hombre de mi vida. Volví al closet de mi compañera y me solté el cabello (por entonces tenía rastas que me llegaban por

9 Artista de performance de origen argentino, radicada en la ciudad de Nueva York. Cook se reconoce como lesbiana feminista, radical y comprometida. Hace monólogos políticos que satirizan a la sociedad estadounidense y su conservadurismo. Para mayor información ver el portal: www.susanacook.com

${ }^{10}$ Diane Torr (2010) utiliza el concepto de alter ego para referirse a los personajes que se ponen en juego en los talleres. 
encima del trasero). ¿Dónde se ha visto a un ejecutivo de traje y corbata con esas rastas? Tomé unos jeans anchísimos, una playera que me iba grande, un chaleco de plumas y un pañuelo rojo. Me lo puse y caminé... femeninamente..., como siempre. Mi compañera me enseñó a ocupar el espacio, andar con las piernas abiertas, prestarle atención a mi nuevo centro: el "paquete". Tuve que repetirlo y repetirlo, ensayar.

Ese fue mi alter ego al día siguiente en el taller y fluyó tanto que la fotógrafa, que llegó cuando ya estábamos vestidos, se preguntaba qué hacía ese tipo en un taller que estaba dirigido a mujeres. Susana rió y yo me sonrojé. ¿Ya "pasaba" por hombre?, ¿qué me había pasado? Me miré al espejo, vi mi barba, mis facciones marcadas, una mirada distinta y más directa, ninguna sonrisa complaciente. ¡Y sí!, parecía un hombre, un chico y, además, un chico malo. Sorpresa, extrañeza, ilusión, un poco de desagrado, duda, hasta miedo... muchas cosas. Cierto sentido de autenticidad, como relatan las alumnas de Torr (196). Sentido de autenticidad que me descolocaba y que ponía en cuestión, a la vez, el sentido de autenticidad de mi performance más cotidiana. Ensayamos durante horas nuestros bailes, así como diferentes situaciones clásicas donde la masculinidad hegemónica se explaya: peleas callejeras, borracheras, partidos de futbol, acoso a las mujeres de la calle...

No me gustaba lo que hacíamos pero sí me gustaba sentirme en ese papel, moviéndome así, mirando así, retando, ocupando todo el espacio, hasta luchando por él. Era diferente y me trataban diferente. En verdad podía ocupar esa posición, aun cuando nunca lo hubiera imaginado porque eso ponía en tela de juicio la unicidad de mi propia identidad: "Si la identidad masculina y femenina pueden convivir en un mismo cuerpo, el concepto de identidad singular, no se diga el de género singular, es puesto en cuestión". ${ }^{11}(197)$

Al tercer día reflexionamos todas juntas sobre qué nos había pasado en las exploraciones. Algunas se habían sentido liberadas, otras ya no volvieron al taller, otras más querían quedarse con su personaje masculino... Pero todas y cada una de nosotras habíamos vivido algo en común: el cuestionamiento de esa performance de género que hacemos día a día, creyendo que fluye y es natural. ¿Performance performativa? Performance que materializa nuestros cuerpos de mujeres, produciéndonos como sujetos generizados.

¿Por qué cuando me siento cruzo las piernas?, ¿por qué muevo las caderas cuando camino?, ¿por qué sonrío a todo desconocido que me mira o me dice algo, aunque sea desagradable?, ¿por qué ocupo el mínimo espacio posible?, ¿por qué miro al suelo?, ¿por qué

11 "If mail and female identities can coexist within the same body, then the concept of singular identity, let alone singular gender, is thrown into question". 
fumo delicada y discretamente?, ¿por qué respiro de a poquito y silenciosamente?, ¿por qué hablo bajito? En mi chico con rastas nadie me miraba, prácticamente me regalaban el espacio para que yo lo ocupara. Algunas mujeres se apartaban medio asustadas, aunque nunca supe si era porque parecía un hombre o por mi pinta de malo.

A mi regreso a Barcelona ya había dos grupos en el Estado español que daban este tipo de talleres: las Medeak ${ }^{12}$ y las O.R.G.I.A. ${ }^{13}$ Me uní a los de las Medeak y seguí compartiendo mis reflexiones corporales con compañeras feministas. Los talleres consistían en compartir los trucos para draguearnos, simular algunas situaciones clásicas y salir a la calle. Pero me faltaba algo, trabajar más con el cuerpo, destrabarlo, desinhibirlo, desmecanizarlo para soltar esa feminidad tan instalada.

Junto con dos aliadas, decidí empezar a investigar y trabajar para poder impartir nuestros propios talleres, convocando en primer lugar a nuestras compañeras feministas. Propusimos, como novedad, centrarnos no en la transformación con las diferentes técnicas sino en el cambio de actitud, posición, eje, movimiento, es decir, en el cuerpo y la reflexión colectiva. Utilizamos técnicas del teatro social para trabajar una primera parte del taller, en la que poníamos en juego nuestros cuerpos "de mujer". Los pusimos a interactuar y luego intentamos des-mecanizarlos mediante ejercicios que convocaban a las risas, cooperación, extravagancias, ridiculeces y demás. Jugábamos con nuestras propias concepciones estereotipadas a través de crear "fotografías" de lo que se nos venía a la mente cuando decíamos palabras como "travesti", "feminidad", "masculinidad", "odio", "amor" y otros términos vinculados directa o indirectamente con las definiciones de los ideales regulatorios de género. Nos confrontamos con imaginarios que a final de cuentas nos constituyen. Después, la gente estuvo dispuesta a dejarse llevar.

Una parte fundamental de estos talleres consiste en la trasformación corporal mediante la ocultación del pecho, la creación y colocación del "paquete" en la entrepierna, el diseño de la barba o bigote, la colocación de vello corporal donde cada king desee y el maquillaje para ensombrecer algunos rasgos faciales.

Aunque la venda elástica es uno de los recursos más fáciles y económicos para aplanar y esconder el pecho, no es el único. Existen fajas deportivas, originalmente dise-

12 Colectivo transfeminista de Donosti (País Vasco) que aprendieron a dar talleres King de la mano de Beatriz Preciado en Barcelona, cuando organizó en 2005 en el MACBA el taller de Tecnologías del Género (http:// www.macba.cat/es/tecnologias-del-genero-micropoliticas-postidentitarias) .

13 Colectivo artístico feminista de Valencia que en 2005 impartió su primer Taller Drag King en contextos académicos/artísticos. Ver referencia en bibliografía.

${ }^{14}$ Mediante la técnica del “Teatro Imagen”, que forma parte del arsenal de metodologías utilizado en el Teatro social o Teatro del oprimido, propuesto por Augusto Boal. 


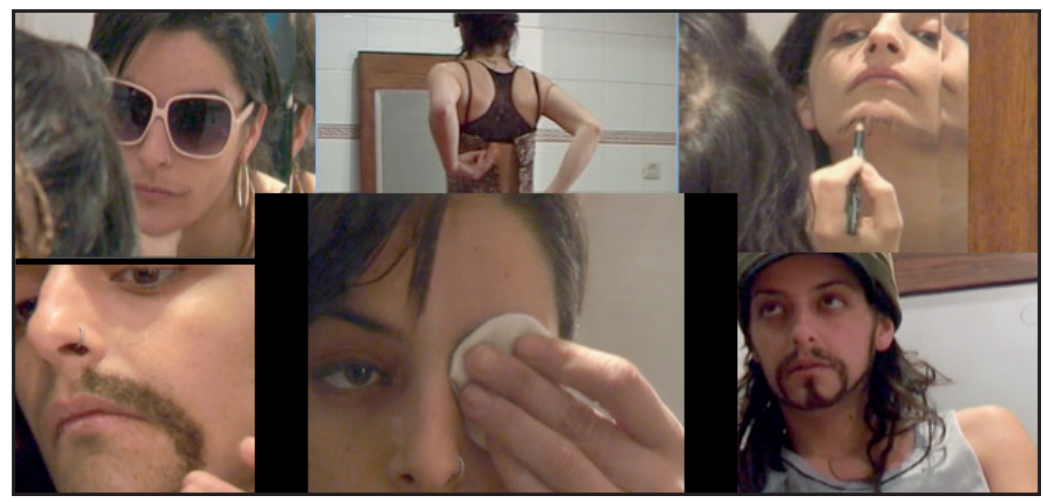

Talleres Drag King. Ciudad de México, México, 2015. Fotografía de Amalia Ospina Palacios.

ñadas para la cintura, que no obstante pueden usarse cómodamente con este fin. Hay también bynders ${ }^{15}$ caseros o comerciales que algunos chicos transgénero suelen utilizar. Por otra parte, hay cuerpos que no necesitan ocultar nada u otros que, por el contrario, tienen que utilizar relleno de espuma de poliuretano en la barriga para disimular unos pechos demasiado grandes, que definitivamente no se puedan aplanar con ninguna de las técnicas mencionadas.

El cambio perceptual provocado por la venda o la faja en el pecho es muy importante. Sentir el busto presionado e inexistente transforma la postura corporal y la sensación, pareciera que el pecho constituye un foco que con su ocultación cambia de lugar y nos obliga a curvar la espalda cerrando los hombros (produciendo un efecto subjetivo que difícilmente se puede describir). Por otro lado, el aprisionamiento de las vendas y la consecuente dificultad para respirar, nos sirve para mantenernos en este otro centro corporal y en nuestro nuevo alter ego. A algunas personas nos gusta esta sensación y otras la detestan, pero lo que está claro es que, más allá de que estéticamente se consiga la ocultación absoluta del pecho, tiene un efecto corporal específico que constituye un marcador de género determinante.

El momento de la fabricación del "paquete" es el que más hilaridad genera y no creo que se trate solo de casualidad, atendiendo a que la risa es un gran indicador de desorden social. En mayor o menor medida, las carcajadas que se desatan durante esta tarea están vinculadas a lo inapropiable de estar fabricándonos un pene para nuestro drag, de estar plagiando el falo (tan cargado simbólicamente y sobrecodificado en términos de género).

${ }^{15}$ Se trata de camisetas interiores elásticas muy fuertes que aplanan el pecho, similares a los brasiers deportivos. 
La técnica al uso es de lo más sencilla: un condón relleno de algodón al que cada tallerista da la forma y tamaño que desee. Se recomienda que sea grande y con una base más ancha - a modo de testículos - que nos permita sentirlo entre las piernas. Ha habido mujeres que no se han atrevido a hacerse paquetes grandes y otras que han verbalizado lo sumamente placentero que les resulta sentir "el roce constante de eso grande entre las piernas". Sin duda, existe mucha diversidad en la manera de relacionarnos con ese "extraño" que va a tomar protagonismo en nuestra performance.

De lo que estoy convencida es de que al sentirlo ahí como un accesorio nuevo y contundente, en constante roce con nuestra zona genital y con la cara interior de los muslos -y sumado a la sensación que produce la ocultación del pecho-, el centro corporal baja. El "paquete" se convierte en nuestro nuevo eje rector y esto modifica tanto la autopercepción como la percepción del entorno. Es como mirar el mundo desde otro lugar, y de hecho se mira al mundo desde otro lugar.

El rostro, que juega un papel primordial en la presentación social y en la identidad, constituye una parte muy importante en la transformación drag. El trabajo con los rasgos faciales es el que exige más detalles y comienza por la visualización. Hay que diseñar el vello facial en función de algún personaje masculino previamente definido, a partir de la observación de diferentes hombres. Dependiendo de lo que queramos, utilizamos trocitos muy finos y pequeños de nuestro propio cabello, o bien algún rímel con el que resaltamos el vello que la mayoría de las mujeres ya tenemos en la cara (cuando no nos depilamos).

Antes de colocar el vello, con un lápiz negro de maquillaje dibujamos sobra la piel nuestra barba, bigote, cejas y/o las patillas. Se marca su recorrido y luego se le difumina con los dedos, para enseguida revestirlo de pegamento facial o gel de pelo y, ahora sí, rellenar con los trocitos de cabello que habíamos cortado previamente. Si bien este ritual se puede hacer de forma individual, un trabajo colaborativo a la hora de hacer las barbas, patillas y bigotes puede constituir un momento perfecto para comenzar a preguntarnos colectivamente por nuestros alter egos: ¿de dónde es este hombre?, ¿cuántos años tiene?, ¿cómo se llama?

La ropa y accesorios vienen después, en un momento en el que el taller rebosa ya de masculinidades plurales en incipiente interacción: gritos, risas, choques de manos, de hombros, mientras se escoge la mejor ropa para cada nuevo personaje. Normalmente, la ropa y accesorios no constituyen elementos centrales para la performance de la masculinidad, pero dotan a cada king de un estilo particular y lo diferencian del resto.

El momento de draguearnos es especial cuando se realiza como ritual colectivo, genera muchas reflexiones y emociones compartidas que posibilitan su incorporación al carácter de cada personaje en construcción. Ninguno de los personajes está aún del todo afianzado, 


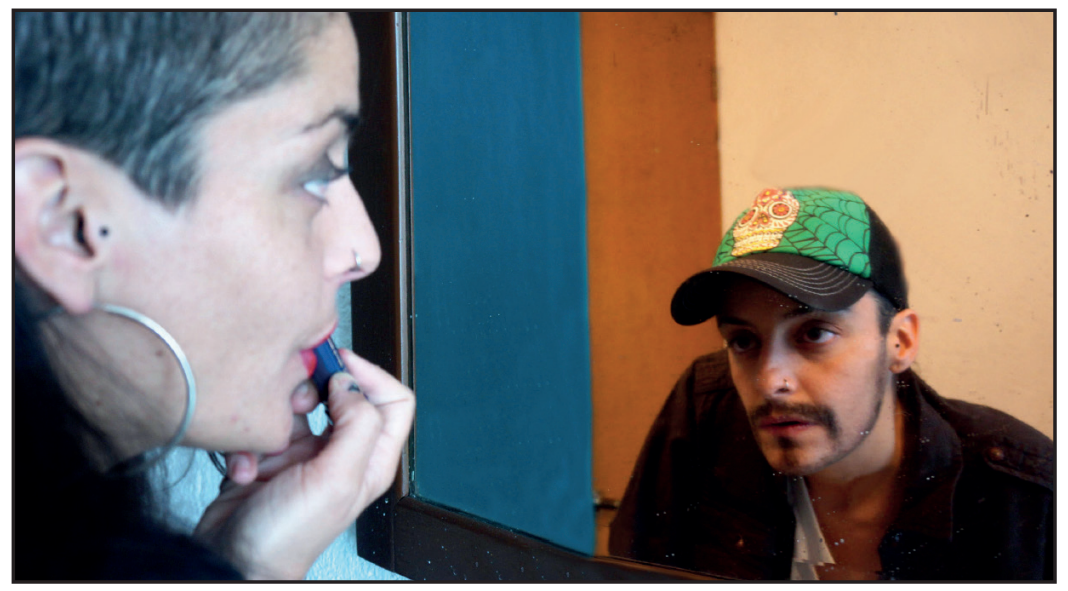

Talleres Drag King. Barcelona, España, 2010. Fotografía de María Berzosa Suescun.

será necesario realizar sucesivos ejercicios para trabajar corporalidades "machas" y lograr la transición corporal hacia los personajes. Se trabaja con el rostro, las piernas, la espalda, los hombros, la cintura, el "paquete", las rodillas y los pies...

En vez de bajar los ojos, se experimenta ahora con una mirada recta, directa, observadora, contundente y por lo general escurridiza (a menos que se quiera retar al otro). Se busca una mirada capaz de ocupar el espacio tal como debe hacerlo el resto del cuerpo. La seriedad que evita la sonrisa complaciente define perfectamente a la masculinidad en un rostro; una seriedad que afila nuestras facciones, las endurece y —-sumada al tipo de mirada descrito- desprende una actitud ruda que se relaciona socialmente con lo masculino. Cuando la vemos en el espejo, esta cualidad nos invita a entenderla como una capa más de la que nos podemos apropiar y con la que podemos jugar.

Los hombros no están rectos ni tensos, más bien caen un poco hacia adelante sobre una espalda que ya no necesita estar erguida como en el ballet clásico. "Relájense chicos, dejen caer sus hombros y su espalda, el centro ha cambiado de lugar, ahora está en el 'paquete". De ahí saldrá la energía que nos moverá ahora por el mundo.

Las caderas dejan de bailar al caminar, lo que se logra mediante ejercicios colectivos de imitación. Las piernas, en vez de mantenerse pegadas como si resguardaran ciertas partes íntimas, permanecen ahora abiertas para darle lugar al "paquete" y para hacerse espacio en el metro, camión o banco del parque. La voz es lo más difícil de trabajar y en los talleres para principiantes no suele lograrse una modulación precisa, pero todo es constantemente una prueba y error. Ayuda por lo general intentar una voz más grave, con mayor volumen y menos titubeos, muy usada. Para alterarla, se realizan ejercicios de exageración, aunque lo difícil es fijar los hallazgos. 
INVESTIGACIÓNTEATRAL

Revista de artes escénicas y performatividad

Vol. 9, Núm. 13

abril-septiembre 2018
Los talleres Drag King: Una metodología

feminista de investigación encarnada

Alba Pons Rabasa

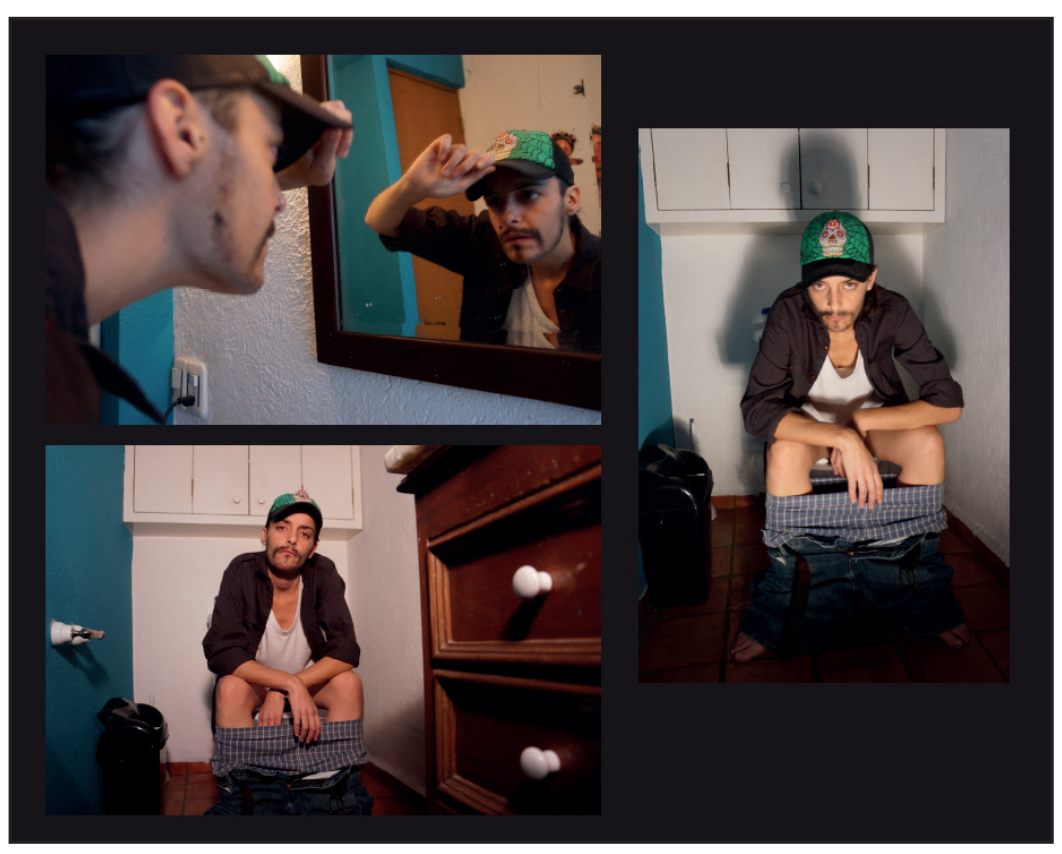

Talleres Drag King. Ciudad de México, México, 2015. Fotografía de Amalia Ospina Palacios.

Todos estos cambios corporales son practicados y repetidos, reafirmados y consolidados a través de ejercicios que ya se habían hecho en la primera parte del taller (cuando todavía no nos habíamos dragueado); esta vez con la intención de construir un alter ego mediante el ejercicio de "la silla caliente". ${ }^{16}$ Después de esto, el nuevo king ya tiene nombre, edad, familia, ocupación, barrio, aficiones.

Después del trabajo con la corporalidad se pasa a los sociodramas (sketches en los que simulamos determinadas situaciones sociales desde nuestra nueva posición). Bailamos, peleamos, bebemos, fumamos, piropeamos, conversamos, etcétera. Es el paso previo antes de sacar a nuestros kings a pasear. Las concepciones que tenemos sobre la masculinidad hegemónica, característica de la cultura de género en la que estamos insertas, florecen desde la sátira, la hipérbole y la parodia: desplegamos la retórica del género.

Es en la calle donde cada nuevo king puede experimentar de verdad la interacción social, ya sea directa o indirectamente, pero con la incertidumbre que implica enfrentarse a lo real. La salida al espacio público genera miedo, pues osamos ocupar una posición que supuestamente no es para nosotras, un lugar supuestamente inapropiable. El miedo a ser

16 Ejercicio de teatro social que se usa para la construcción de personajes. Consiste en colocar una silla al centro del círculo de participantes, donde se sienta uno de ellos mientras el resto le pregunta las características de su personaje. El interrogado debe responder lo más rápida y espontáneamente que pueda. 
descubiertas en tal ultraje suele estar presente durante los primeros momentos de nuestra performance, hasta que poco a poco nos vamos relajando y percatando de que se trata de un lugar perfectamente apropiable. Esa misma apropiación puede incluso transformarse o teñirse de tonos diferentes a los habituales.

Los bares son espacios idóneos para poner a prueba a nuestros alter egos. Al notar alguna señal que meta duda sobre la "veracidad" de sus nuevos compañeros de cantina, los jóvenes comunes con quienes interactuamos suelen desubicarse profundamente. Podría contar miles las anécdotas callejeras llenas de risas y reacciones de lo más variopintas por parte de los hombres "de verdad". Sorpresa, confusión, desorden... son algunas de las emociones que emergen en el instante mismo en que, una identidad que la excede, impacta contra la cultura dominante de género. Reacciones que se explican porque esta extraña identidad, en vez de citar a la cultura de género para reproducirla tal cual, la refleja para parodiarla y poner en evidencia su condición ideal o fantasmagórica (ver Butler, El Género y Cuerpos que importan).

Las caras de sorpresa, sin embargo, se presentan en menor cantidad que las caras de indiferencia, alterando nuestros propios esquemas. Nos desequilibra tener la capacidad de pasar inadvertidos, no ser observados fijamente en la calle, cuando estamos habituadas a ser el centro de atención en los espacios públicos (que parecieran estar dispuestos como pasarelas para el discurrir de nuestra feminidad). Pasar de ser espectáculo a espectador es uno de los grandes cambios que el King nos permite experimentar, asociado a la recién descubierta posición del "hombre": aquel que observa y objetualiza desde una posición de dominio.

Durante la reflexión colectiva que tiene lugar al final del taller, se comparten todas las emociones generadas tanto por la trasformación física como por el cambio de posición social. Muchas mujeres se sienten liberadas y asocian la percepción de poder que supone la transformación, directamente con la libertad. Al respecto, hay que mencionar que las talleristas que piden ropa y accesorios prestados a sus parejas varones para los ejercicios, frecuentemente reciben de ellos burlas y/o desprecio; en respuesta a lo cual -y después de haber sentido en el trabajo dicha "liberación" - muchas veces deciden volver a casa como kings. También hay mujeres que sienten rechazo en esta posición de poder, algo que puede estar mezclado con el morbo o incluso con una sensación de auto-empoderamiento erótico. Cada taller Drag King, en suma, genera reacciones emocionales sumamente plurales.

En el caso de las lesbianas masculinas que participan, suelen terminar performando masculinidades diferentes - y curiosamente más afeminadas - a las que desempeñan cotidianamente. Trabajadoras sociales y enfermeras se abandonan a la tentación de parodiar a sus pacientes hombres, sanando mediante este ritual la sobrecarga de expectativas y presiones sociales inherente al rol social que implica su trabajo. 
Paradójicamente, en todos los talleres hemos terminado reflexionando sobre la feminidad. Al cotejar nuestras vidas cotidianas con lo vivido en las experimentaciones drag, conseguimos analizar desde un lugar de conciencia diferente nuestras situaciones diarias. Se vuelve entonces posible comenzar a reflexionar sobre cuestiones y sutilezas que, al estar confundidas con la normalidad, anteriormente resultaban invisibles o incuestionables. ¿Por qué nunca me quejo cuando en el metro voy sentada entre dos hombres con las piernas totalmente abiertas, mientras yo apenas y quepo en el asiento? ¿Por qué me vuelvo el centro de atención al entrar en un bar o en un autobús? ¿Por qué sonrío siempre a quien simplemente me pregunta la hora o incluso a quien me echa un piropo que no me gusta? ¿Por qué me siento mal cuando reclamo mi espacio o mi libertad de no sonreír? ¿Por qué me siento con las piernas cruzadas y ocupando el mínimo espacio posible al llegar al cine, incluso si no hay mucha concurrencia? ¿Por qué intento estornudar o reír de la manera más silenciosa posible, cuando supuestamente se trata de gestos instintivos?

\section{Apuntes para una autoetnografía drag II. Reflexiones analíticas encarnadas}

La técnica drag king desestabiliza las fronteras de los sujetos que hemos crecido como "niñas-niñas" o como "niñas-menos-niñas", los límites que restringen nuestros movimientos corporales, gestos e incluso nuestras reacciones más instintivas. La nueva percepción de posibilidades corporales y subjetivas que ella convoca, evidencia la cualidad "múltiple y mutable del self" (Torr y Bottoms, Sex, Drag 197). Las utilidades cotidianas son muchas, por ejemplo, mejores recursos para defendernos de las microagresiones o agresiones machistas a las que estamos sometidas continuamente en los espacios sociales predominantemente masculinos. Una calle de noche puede recorrerse de otra manera: podemos pasar inadvertidas, caminando abiertamente, ocupando el espacio, con los hombros caídos y la espalda ligeramente encorvada.

Las múltiples modalidades de experiencia resultantes de cada taller suelen saturar la taxonomía de Halberstam, mostrando la gran diversidad de masculinidades disponibles y la posibilidad de apropiarnos de la posición que todas ellas comparten. No damos por sentada la relación entre los hombres y la masculinidad, así como tampoco se busca ser "hombres por un día"17 (a la manera de Torr). La metodología desarrollada pretende, por el contrario, que "por un día dejemos de ser mujeres". Las reflexiones corporales y sus efectos

17 Título del taller que Diane Torr lleva impartiendo desde 1990. 
en nuestros procesos de encarnación del género son lo verdaderamente relevante. En los talleres se exploran nuevos sentidos de la subjetividad a partir de ocupar la posición de sujeto drag king, "como representación de un identificación transgenérica [que lo que] pone de relieve es la desestructuración de la cadena identificatoria legítima para cierto orden cultural" (Sabsay, "La performance Drag” 5).

No es, pues, que en los talleres hayamos "sido hombres", pero performar masculinidades plurales, más o menos hiperbólicas, más o menos paródicas, nos ha permitido generar un espacio inédito de reflexión sobre la autenticidad de nuestras feminidades supuestamente originales y naturales. Al quitarnos de encima unas capas y ponernos otras, hemos entendido que nuestra performance cotidiana de género es tan construida, limitada y plagiada como la que producimos artificialmente en los talleres. A partir de la reflexión corporal que supone modificar tu centro, mirada, voz, manera de ocupar el espacio - y observando los cambios que se producen inmediatamente en el entorno y las interacciones que lo habitan-, hay una concienciación del proceso mediante el cual somos lo que somos, resquebrándose así algunas de las certezas que nos sostenían identitariamente.

El drag king me ha permitido concienciar cómo mi subjetividad, corporalidad y experiencia exceden, saturan y tensionan cualquier categoría identitaria. La masculinidad y lo que se socialmente le asocia (libertad de elección, autonomía, presencia, etcétera) ha dejado de ser un terreno o posición que yo perciba como inapropiable; ha dejado de ser lo ajeno o lo otro. Recíprocamente, mi "feminidad corporal" ha dejado de ser también inherente a mi genitalidad, algo inevitable e incuestionable.

Más en general, he dejado de percibir como propiedad exclusiva de cada sujeto y algo determinado por sus características sexuales, todo aquello vinculado a la feminidad, masculinidad e incluso a la heterosexualidad. Pero lejos de ser meramente discursivo, reitero, este proceso de concienciación parte de una reflexividad corporal provocada por la experiencia drag. ¿Cómo podríamos aplicar estos aprendizajes encarnados a la producción feminista de conocimiento? ¿Cómo se puede encarnar la investigación?

Entiendo al drag king como una práctica corporal en los términos de Elsa Muñiz (2010), ${ }^{18}$ que en tanto performativa, participa en el proceso de materialización de los sujetos. Pero a diferencia de otras prácticas corporales, esta no tiende a generar cuerpos dóciles

18 Elsa Muñiz (2010) las define como "los productos y los efectos al mismo tiempo que causas productoras de aquello que producen, que es el cuerpo" (Disciplinas y prácticas 47), entendido este último como complejidad, "un continuo entre la biología y la cultura [...] como punto de partida y llegada del proceso de materialización producto de la performatividad, que está dada por los discursos que producen representaciones y las prácticas corporales cotidianas y ritualizadas que producen cuerpos dóciles, maleables y controlables" (46). 
sino que irrumpe en la lógica secuencial del género, la cual pretende estabilizar al sujeto objetivándolo y adjudicándole la obligatoria coherencia entre cuerpo, género y deseo. Si bien no es capaz de transformar los cuerpos de forma definitiva, abre una brecha para la problematización de lo que es y significa la identidad de género, posibilitando así cambios conscientes en nuestra performance cotidiana.

Como efecto performativo, la técnica drag suscita una problematización corporal y subjetiva que modifica la forma de experienciar la identidad propia $y$, por tanto, de percibir y habitar el mundo. Esto vuelve evidentes cuatro procesos que conllevan un necesario replanteamiento del uso del concepto de identidad de género en términos analíticos y políticos, los cuales resultan cardinales para el análisis teórico que aquí pretendo compartir.

Mediante la performance de la masculinidad, que problematiza la performance cotidiana de la feminidad, nos percatamos de que no existe una forma unívoca de corporalidad ni de subjetividad que responda a la representación social que producen las categorías identitarias. Éstas quedan siempre desbordadas, incluso por la serie de estrategias que cualquier persona pone en juego al quedar vinculada a ideales regulatorios del género, (pues cada individuo se relaciona espontáneamente con éstos a través de una experiencia vital que los vuelve vivibles, no mediante una performance que los cite a la perfección). Al dramatizar o representar figuras de la retórica del género distintas a las que acostumbramos cotidianamente, se evidencia que toda experiencia corporal y de género tensiona las categorías identitarias.

Solo entonces se hace posible cuestionar la originalidad, singularidad y esencialidad de la propia identidad. Pues si puedo salir a la calle dragueada y ser tratada como un hombre, consiguiendo apropiarme de ciertos gestos, movimientos, sensaciones y prácticas que se asocian socialmente a la masculinidad -y si además descubro que la ocupación de esta otra posición social no me está vedada y que todo ello tiene un efecto de autenticidad-, entonces mi performance cotidiana de la feminidad no es inherente a mi naturaleza corporal ni dicha naturaleza podría manifestarse a priori. Significa, a la vez, que las posiciones estructurales de dominio no están completamente determinadas por las características de los sujetos que las ocupan, sino que por el contrario, la investidura en dichas categorías confiere ciertas características que configuran la posición misma de dominio. La posición social que ocupo nunca es fija ni está suturada, el campo social no puede quedar totalmente establecido (Mouffe y Laclau, Hegemonía y estrategia 193).

El Drag saca a la luz algo que normalmente permanece oculto en el campo de lo social, a saber, el proceso de materialización de los cuerpos mediante el cual no solamente devenimos sujetos, sino además sujetos de género, raza y clase social. Los talleres nos han llevado a descubrir que no se puede ser un "hombre a secas", y por tanto también a preguntar si puede acaso pensarse en un sujeto sin género. Más aún, ¿es posible la subjetivación fuera 
de la inteligibilidad que confieren las matrices normativas de significación relacionadas con el género, sexualidad, raza, clase e incluso la edad?

De acuerdo con Judith Butler (en su relectura de Foucault) no hay sujeto que se constituya al margen de dichas matrices. En su seno, cada uno se da su propio exterior constitutivo, ${ }^{19}$ lo que además hace que tales categorías sean contingentes e inestables, estando siempre en constante reformulación (Butler, Cuerpos que importan 63). Esta misma contingencia, de hecho, es la que produce cierto efecto de apertura, responsable en última instancia tanto de la eficacia performativa como de la brecha de posibilidad de subversión y/o resignifación (172).

Al hacer consciente la naturalización mediante la cual fijamos una identidad, aquélla pierde parte de su eficacia performativa, es decir, se debilita aquello que permite que la misma enunciación naturalizada se constituya como real (Sabsay, "El Sujeto" 161). ${ }^{20}$ La desencialización y la desnaturalización de la identidad devienen entonces un proceso de desubjetivación, que lejos de darse de forma pura, consciente y cerrada, se combina con el constante proceso de subjetivación de género en el que estamos irremediablemente insertas en tanto sujetos. Pensemos en cómo Foucault (1995) y más tarde Butler (2002 [2001]), trabajan sobre la crítica como virtud, es decir, como posibilidad de desujeción de la norma. El drag king nos permite encarnar esta crítica, reflexionarla corporalmente desde la experiencia. Es por ello que puede concebirse ya no solo como herramienta de concienciación feminista, sino también como técnica de investigación encarnada.

$\mathrm{Su}$ uso obliga a problematizar esa concepción fija y estable que se desprende de las categorías identitarias en concreto, y del concepto de identidad en general. Los excesos, tensiones, resignificaciones y el desbordamiento, cuestionan ciertos esquemas analíticos que objetivan la experiencia y producen representaciones sociales (como las identidades y la concepción de sujeto misma que les subyace), las cuales sirven a su vez de referente para la resubjetivación. En la citación cotidiana de tales referentes, los sujetos entran en un proceso infinito en el cual pierden totalmente su agencia, capacidad de contestación y posibilidades de resistencia. ${ }^{21}$

19 Es Chantal Mouffe quien recupera las nociones derridianas de supplement, trace y différance y elabora la idea de exterior constitutivo para "mostrar el carácter de relación de toda identidad y el hecho de que con frecuencia la constitución de una identidad implica el establecimiento de una jerarquía" ("Por una política” 6). Para profundizar al respecto, revisar Chantall Mouffe, 1996.

20 Para profundizar en la eficacia performativa ver Sabsay, "El Sujeto" 2009, 165-175.

21 En "Una biopolítica menor: entrevista con Giorgio Agamben" (1999), este filósofo italiano, recuperando la definición de biopoder foucaultiana, nos habla sobre la capacidad de resubjetivar que tiene la maquinaria estatal, así como de insertar al sujeto en un proceso infinito de resubjtivaciones que es el que justamente define al biopoder. 
No es que proponga el voluntarismo identitario por el que se ha criticado a Butler y a la teoría queer en tantas ocasiones, ni que obvie el carácter estructural inherente a las posiciones sociales. La propuesta es más bien que, partiendo de estas reflexiones teóricas encarnadas, la investigación feminista gane claridad sobre cómo aprehender los procesos mediante los cuales nos constituimos en sujetos encarnados y de género, con tal de evitar producir nuevamente discursos objetivantes, categorías fijas y coherencias normativas. Se trata de promover una concepción del sujeto como existencia compleja, multidimensional y encarnada, ya no meramente subyugado a los marcos de regulación social sino en diálogo y disputa con ellos, desde una reflexividad corporal radical inmersa en procesos - conscientes o no- de reapropiación subversiva de algunos de sus presupuestos y tecnologías.

Dicha concepción de un sujeto complejo y en constante movimiento, invita a pensar su imbricación con la corporalidad. Reconocido en términos de experiencia, el cuerpo en tanto corporalidad y sujeto permite hablar de una cultura encarnada (Csordas, "Embodiment" 36-37). Si el género se produce mediante una estilización del cuerpo que obedece a una ilusión de coherencia - la cual se consigue a través de la significación que confiere la matriz heterosexual (Butler, El Género 38)-, así como de una repetición reiterada de actos que materializan a los cuerpos - dividiéndolos en aquellos que importan y aquello que no-, el Drag King irrumpe poniendo en cuestión la existencia y supuesta naturalidad de un original previo a la performance drag. Esto implica desestabilizar la continuidad entre cuerpo, género y deseo, evidenciando la complejidad, inestabilidad y multidimensionalidad tanto de la identidad como de los procesos de encarnación del género.

Lo cual confirma la manera en que Butler entiende la identidad, a saber, como una ficción normativa que opera estabilizando al sujeto y haciéndolo aparecer como esa entidad estable, cuando en el fondo dicha representación no es más que el efecto de una posición adquirida por el propio sujeto. Lo interesante de irrumpir en esta operación es evidenciar cómo las posiciones del sujeto son múltiples, inestables y contingentes, al contrario de lo que la propia noción de identidad nos permite aprehender (Mouffe y Laclau, Hegemonía y estrategia 194-196). Ello no quiere decir que tales posiciones no sean estructurales, sino que en tanto que tales, su apropiación está condicionada y condiciona al mismo tiempo las performances cotidianas configuradas por las matrices no solamente de género, sino también de racialidad, clase social, sexualidad, capacidades corporales e incluso religiosidad. Pero el hecho de que esta apropiación esté condicionada normativamente, reiteremos, no implica que las posiciones sean estables ni que los sujetos no podamos reapropiarnos estratégicamente de ciertos referentes, construyendo con ello rutas de inteligibilidad que acaban resignificándolos o incluso torciéndolos. 
Esta perspectiva teórica pide replantear el modo como la propia investigación feminista emplea el concepto de género. Son numerosos y necesarios los estudios que lo abordan en tanto dispositivo regulador, normatividad, tecnología de control y sujeción. Quizá sea preciso, además, promover esfuerzos que también estudien etnográficamente las estrategias y prácticas mediante las cuales, en sus respectivos procesos de encarnación, los sujetos resisten, contestan y tensionan esa dimensión normativa en pos de existencias más vivibles.

Si bien no es posible colocarse fuera de los procesos de subjetivación o de la inteligibilidad, ese tipo de esfuerzos podría resultar sumamente estimulante al permitirnos observar la complejidad con que tales estrategias y prácticas - así como los efectos que producen - se articulan con los procesos de interpelación normativa que también nos constituyen. Probablemente, ahí encontraremos otras rutas de inteligibilización subjetiva y corporal a las que es importante atender por su potencialidad cuestionadora y capacidad transformadora.

El reto es crear herramientas que nos permitan aprehender, potenciar y analizar desde una perspectiva crítica encarnada, la multiplicidad de experiencias y prácticas implicada en los procesos de encarnación sexo-genérica que cuestionan la concepción de sujeto subyacente a las políticas sexuales contemporáneas. El drag puede ser una de ellas.

\section{Dragueando la investigación feminista: el drag como técnica de investigación encarnada}

Utilizar al drag como técnica de investigación encarnada ${ }^{22}$ nos permite analizar cómo opera el género - así como otros ejes subjetivantes, en diferentes niveles - tanto en nuestro campo de investigación como en nuestras relaciones. Hace posible reflexionar además en cómo el género atraviesa el planteamiento de nuestros proyectos, el desarrollo del trabajo de campo y la producción del análisis y escritura. Desgranar esta operación posibilita la apertura de un nivel de reflexividad crítica en torno a lo epistemológico, desestabilizando las oposiciones binarias a través de las cuales miramos y hacemos inteligible el mundo y a nosotras como parte del mismo. Utilizar al drag como técnica de investigación es poner al cuerpo en nuestros trabajos, repensar la investigación y

${ }^{22}$ La invitación a utilizar el drag como técnica de investigación encarnada va dirigida en primer lugar a las investigadoras, quienes después de vivir la experiencia en primera persona podrían a su vez llevarla a las personas con quienes cada una trabaja. Pero, principalmente, me refiero a experimentar esta técnica en el cuerpo propio como una herramienta de reflexividad. 
entenderla como práctica corporal y transformación personal, desplazarnos por las diferentes posiciones que en nuestra investigación ocupamos de una forma consciente y estratégica.

Al investigar sobre el proceso de normalización de lo trans* en la Ciudad de México y los procesos de constitución corporal y subjetiva de personas a las que dicha normalización interpela, ${ }^{23}$ la experiencia de draguearme e impartir estos talleres me ha permitido poner en tensión la frontera entre mi yo-investigadora y las personas que se han acercado a compartir mi trabajo. La desestabilización de esta oposición binaria se ha dado asumiendo la distancia y diferencia experiencial respecto a ellas, pero también desde aquellos lugares comunes que a fin de cuentas facilitan, no una apropiación de las historias ajenas, sino una conversación con ellas. De esa forma he logrado "sentipensar" lo que las talleristas relatan, intentando que mi investigación sea un lugar colectivo de producción de conocimiento situado.

Investigo lo trans* como lugar privilegiado desde el cual mostrar el carácter contingente, constituyente y constituido del género, que el drag king evidencia a través de la experiencia corporal colectiva. El objetivo no es tanto analizar los procesos de encarnación genérica (como algo de lo que podamos sacar un modelo social a extrapolar a otras identidades notrans*), sino más bien mostrar la particularidad de los procesos vivenciales de género de cada sujeto y ponerla en diálogo con la generalidad de la lógica social de una determinada cultura de género que nos atraviesa a todas (trans* o no) y con cuyos presupuestos lidiamos de una forma u otra.

Pensar el drag king como técnica de investigación encarnada incita a mantenernos en una postura crítica y de continua reflexividad respecto a nuestro propio lente analítico, indudablemente permeado por nuestra subjetividad y corporalidad. Al mismo tiempo, nos permite comprender desde el cuerpo que la producción de conocimiento en torno a la materialización de los sujetos debe virar necesariamente hacia una producción que no objetive las experiencias, que atienda a la compleja articulación entre la experiencia y sus propias representaciones, contemplando que nuestra tendencia espontánea en tanto sujetos, no es una citación perfecta de los ideales regulatorios sino la búsqueda y constante construcción de un modo de existencia vivible.

Los cuatro procesos antes mencionados (el desbordamiento constante e ineludible de las categorías identitarias, el cuestionamiento a la esencialidad y originalidad de la identidad, la toma de consciencia sobre la inexistencia de un a priori subjetivo y material,

${ }^{23}$ Investigación doctoral en el Departamento de Ciencias Antropológicas de la UAM-Iztapalapa titulada "De las transformaciones sociales a las micropolíticas corporales: un archivo etnográfico de la normalización de lo trans* y los procesos de corposubjetivación en la Ciudad de México". 
así como sobre la desnaturalización y el carácter interseccional de la identidad) pueden ser incorporados a nuestra experiencia e investigaciones por medio del drag, como presupuestos inapelables en torno al género y la identidad en la investigación feminista. Finalmente, el drag nos permite analizar las posiciones sociales como lugares contingentes y estructurales al mismo tiempo, es decir, asumir que si bien se trata de posiciones que responden a una determinada estructura de poder, la apropiación de las mismas resulta posible y contingente.

Si por un lado las representaciones que este tipo de trabajos de investigación producen pueden devenir recursos de inteligibilidad inevitablemente relacionados con lo normativo, por el otro van más allá de ello y nos permiten asumir la potencialidad de transformación que contienen los procesos de encarnación sexo-genérica. Corporalizar nuestros análisis nos permite hacer más porosas las fronteras disciplinarias desde las que pensamos, así como asumir el compromiso político en función de una transformación social y personal, que permita la desestabilización de la cultura de género binaria que invariablemente resulta excluyente y violenta a los sujetos.

Este artículo es una invitación a perder el miedo a traspasar esos límites corposubjetivos $^{24}$ recreados constantemente por los ideales regulatorios, que tendemos a encarnar y reproducir no solamente en nuestra corporalidad sino también, de manera no consciente, en los trabajos de investigación que llevamos a cabo. El drag king nos permite interrumpir estas reiteraciones que cotidianamente son responsables de la producción del género, problematizándolo y analizando el poder performativo que lo sedimenta corporalmente. Permite la dilución de fronteras corporales, el resquebrajamiento de los límites subjetivos, la apropiación y resignificación de los elementos que conforman los ideales regulatorios pero desde la torsión y la tensión de los mismos. El drag king permite el hundimiento de las certezas identitarias y, por tanto, la apertura y la posibilidad de problematizar cómo éstas atraviesan nuestras propuestas de investigación feminista.

24 En otros trabajos (Pons, "From representation" y "De las transformaciones") propongo la corposubjetivación como el proceso mediante el cual las subjetividades se van encarnando y en el que las representaciones sociales en torno al género, racialidad y clase participan performativamente de forma compleja, particular y constante. Se trata de un movimiento continuo de transformación material del complejo entramado corporal, subjetivo y cultural que implica el sujeto en relación a su contexto. De hecho, en este proceso se entrecruzan diferentes niveles de la experiencia que afectan, modelan y producen "la carne" y al mundo en el continuum que ambos constituyen. 


\section{Bibliografía}

Agamben, Giorgio. "Una biopolítica menor: Entrevista con Giorgio Agamben”. Trad. Javier Ugarte Pérez. Vacarme, n.ำ10, 1999, en línea.

Butler, Judith. El Género en Disputa. El feminismo y la subversión de la identidad. Barcelona: Paidós, 2007 [1990].

Butler, Judith. Cuerpos que importan. Sobre los limites materiales y discursivos del "sexo". Argentina: Paidós, 2002 [1993].

Butler, Judith. “¿Qué es la crítica? Un ensayo sobre la virtud de Foucault”. The Political: Readings in Continental Philosophy. Ed. David Ingram. Londres: Basil Blackwell, 2002 [2001].

Csordas, Thomas J. "Embodiment as a Paradigm for Anthropology”. Ethos, vol. 18, núm. 1, 1990, pp. 5-47.

Ellis, Carolyn; Adams, Tony E.; Bochner, Arthur P. "Autoetnografía: un panorama”. Astrolabio, n. 14, 2015, pp. 249-273.

Ellis, Carolyn y Arthur P. Bochner. "Autoetnography, personal narrative, reflexivity: research as subject". Handbook of qualitative research, eds. Norman Denzin e Yvonna Lincoln. California: Sage, 2000, pp. 733-768.

Halberstam, Jack/Judith. Masculinidad Femenina. Barcelona-Madrid: Egalés, 2008.

Foucault, Michel. “¿Qué es la crítica?”. Revista de Filosofía, núm.11, 1995, pp. 5-25.

Mouffe, Chantal y Ernesto Laclau. Hegemonía y estrategia socialista. Hacia una radicalización de la democracia. Madrid: Siglo XXI, 1987.

Mouffe, Chantal. "Feminismo, ciudadanía y política democrática radical". Feminist Theorize the Political, ed. Judith Butler y Joan W. Scott. Nueva York-Londres: Routledge, 1992.

Mouffe, Chantal. "Por una política de la identidad nómada”. Debate Feminista, vol. 14, 1996, pp. 3-13.

Muñiz, Elsa, coord. Disciplinas y prácticas corporales. Una mirada a las sociedades contemporáneas. Barcelona-Ciudad de México: Antropos, Universidad Autónoma Metropolitana-Azcapotzalco, 2010.

Pons Rabasa, Alba. "From representation to corposubjetivation: the configuration of transgender in México City”. Transgender Studies Quarterly, Translating Transgender. Tucson: Duke Press, 2016.

Pons Rabasa, Alba. "De las transformaciones sociales a las micropolíticas corporales: un archivo etnográfico de la normalización de lo trans* y los procesos de corposubjetivación en la Ciudad de México”. Tesis de doctorado, Universidad Autónoma Metropolitana-Iztapalapa, 2016. 
INVESTIGACIÓNTEATRAL

Revista de artes escénicas y performatividad

Vol. 9, Núm. 13

abril-septiembre 2018
Los talleres Drag King: Una metodología

feminista de investigación encarnada

Alba Pons Rabasa

Preciado, Beatriz. "Género y performance (tres episodios de un cybermanga feminista queer trans...)". Revista Zehar, núm 54, 2004, pp. 1-14.

Sabsay, Leticia. "La performance Drag King: usos del cuerpo, identidad y representación". Revista Questión, núm. 12, 2006, en línea.

Sabsay, Leticia. "El Sujeto de la Performatividad: Narrativas, Cuerpos y políticas en los límites del género". Tesis de doctorado, Universidad de Valencia, 2009.

Taylor, Diana. Performance. Buenos Aires: Asunto Impreso, 2012.

Torr, Diane y Stephen Bottoms. Sex, Drag and Male Roles. Investigating gender as performance. Michigan: University of Michigan Press, 2010.

Volcano, Delagrace y Jack Halberstam. The Drag King Book. Londres: Tail, Serpent's, 1999. 